\title{
Progress-Defining Risk Factors for Stroke Prevention
}

\author{
Craig S. Anderson
}

The George Institute for Global Health, Faculty of Medicine, University of New South Wales, Sydney, NSW, Australia

In this issue of the journal, Azarpazhooh, Bogiatzi, and Spence kick off our 30-year celebration series of commissioned articles with an overview of some controversial or neglected aspects of stroke prevention [1]. The last 30 years has seen unprecedented growth in our understanding of risk factors and developing strategies to prevent stroke. To a large extent, this has arisen from advances in the scope of epidemiology to define "the distribution and determinants of health-related states or events in specified populations, and the application of this study to control of health problems" [2]. This has allowed us to appreciate that strokes are not only a leading cause of death and disability worldwide [3] but also that incidence rates vary dramatically according to age, right up to the "oldest old" (i.e., beyond the earlier broad categorization of being elderly as $\geq 65$ years), between men and women (i.e., women have tended to be excluded from research), and from one population to another in relation to heterogeneity in the pattern of pathological subtypes (i.e., defined through advances in imaging and other technology) and prevalence of risk factors (i.e., now recognized to be determined by an interplay of genetic, clinical, and socioeconomic factors). To this end, we have come to realize that simply defining risk factors based on binary "normal" versus "abnormal" classification systems (e.g., hypertension, diabetes mellitus, smoker, and obesity) is somewhat arbitrary, restrictive, and open to change with new knowledge. When viewed as continuous exposures (e.g., diet, exercise, sleep, cigarette smoking, alcohol consumption, blood

karger@karger.com

(c) 2021 S. Karger AG, Basel

www.karger.com/ced

Karger" pressure, BMI, and blood glucose and lipid levels), the strength and consistency of associations with outcomes can be more clearly defined [4]. This can produce evidence from well-designed studies, especially if conducted in a variety of locations that can provide the necessary support for developing public policy with the aim of producing broad health benefits across the whole population and for strategies that target individuals with elevated risk.

Yet, despite having shown stroke is largely a preventable condition [5], there are considerable challenges to implementing strategies for reducing the global burden of disease, particularly in low-middle-income countries where people have poor access to effective treatments in healthcare systems that are disjointed and inadequately resourced. Although large-scale multicenter randomized controlled trials can provide the most reliable evidence on the effectiveness and cost-effectiveness of treatments and management strategies, they are expensive and challenging to undertake, and generally only provide limited data over short-term horizons in carefully selected participants. Observational studies are also required to determine risks, and prevention and treatment strategies, but unfortunately, they only show associations, and there is no completely reliable way of assessing whether an observed association of a factor and an outcome is causal or not. Causal inference is therefore usually tentative, and judgments are required based on the available varying levels of evidence, with the likelihood for some degree of ongoing uncertainty.

Correspondence to:

Craig S. Anderson, canderson@georgeinstitute.org.au 
Azarpazhooh, Bogiatzi and Spence [1], and the latter in particular, who has devoted much of his long clinical research career to stroke prevention, have drawn our attention to avenues for enhancing public health strategies, personalizing therapies according to the balance of potential benefits and harms, and in defining avenues for future research.

\section{Conflict of Interest Statement}

C.S.A. acknowledges receipt of research grants from the $\mathrm{Na}-$ tional Health and Medical Research Council (NHMRC) of Australia and the Medical Research Council (MRC) of the United Kingdom, and Takeda paid to his institution.

\section{References}

1 Azarpazhooh MR, Bogiatzi C, Spence JD. Stroke prevention: little-known and neglected aspects. Cerebrovasc Dis. 2021.

2 Last JM. A dictionary of epidemiology. 2nd ed. Oxford: Oxford University Press; 1988.

3 Krishnamurthi RV, Ikeda T, Feigin VL. Global, regional and country-specific burden of ischaemic stroke, intracerebral haemorrhage and subarachnoid haemorrhage: a systematic analysis of the Global Burden of Disease study 2017. Neuroepidemiology. 2020;54(2):171-9.
4 Mozaffarian D, Fahimi S, Singh GM, Micha R, Khatibzadeh S, Engell RE, et al. Global sodium consumption and death from cardiovascular causes. N Engl J Med. 2014;371:624-34.

5 O'Donnell MJ, Xavier D, Liu L, Zhang $\mathrm{H}$, Chin SL, Rao-Melacini P, et al. Risk factors for ischemic and intracerebral hemorrhagic stroke in 22 countries (the INTERASTROKE study): a case-control study. Lancet. 2010; 376:112-23. 